\title{
Anxiety among Staff Members and Workers in Maamoura Mental Hospital
}

\author{
Ehsan.M.Fahmy, H.M.Sery, Shewikar.T.El Bakry and Esraa.M.Shebl
}

Neuropsychiatry, Dept., Faculty of Medicine, Benha Univ., Benha, Egypt

E-Mail: esraahamed1610@gmail.com

\begin{abstract}
Anxiety disorders defined by excess worry, hyperarousal, and fear that is counterproductive and debilitating are some of the most common psychiatric conditions in the Western World. Anxiety is an emotion characterized by an unpleasant state of inner turmoil often accompanied by nervous behavior, such as pacing back and forth, somatic complaints, and rumination. Physicians and nurses are affected by a variety of stressors in their work places because of their responsibility to provide health and treatment to patients. Factors causing anxiety among workers are increasing, and psychosocial causes are the most common. The aim of the study is to estimate the prevalence rate of anxiety among staff members and workers in Mental Hospitals (Maamoura Hospital) and to assess the possible factors that might lead to anxiety among staff members and workers in Maamoura Mental Hospital, and to compare between staff members in Mental and general Chest Hospital regarding anxiety level. From Al Maamoura Mental Hospital 60 subjects and 120 from Al Maamoura Chest Hospital were recruited. Taylor Anxiety rating scale was used to assess the anxiety levels. The prevalence of anxiety in Al Maamoura Mental Hospital on Taylor anxiety rating scale was $(76.8 \%)$ with different degrees versus $56.6 \%$ in the chest Hospital.
\end{abstract}

Keywords: Anxiety, Factors of anxiety, Mental Hospital, Staff Members and Workers

\section{Introduction}

Anxiety is an emotion characterized by an unpleasant state of inner turmoil, it is subjectively unpleasant feelings of dread over anticipated events, such as the feelings of imminent death.[1]

Anxiety is a feeling of uneasiness and worry, usually generalized and unfocused as an overreaction to a situation that is only subjectively seen as menacing.[2]

Work itself is not usually considered as the sole cause of psychic disorders but it may decompensate vulnerable states of psychic stability.[3]

Stress levels among professional nurses have increased due to the increased demands of clinical nursing in recent years. There is an association of work demands and stress [4].

Doctors by the virtue of their job are at enhanced risk of carrying mental health challenges which may cause or exacerbate anxiety and depression. [5]

Physicians are vulnerable to some mental disorders such as anxiety, depression, and occupational burnout, likely owing to their exposure to high levels of occupational stress [6].

A study among nursing professionals revealed that situations in the work environment can provoke anxiety, particularly, among countless circumstances, the instability or aggravation of patients' health condition, lack of material, equipment and staff, relation with patients' relatives, as well as nursing care systemization difficulties and high complexity procedures [7].

Anxiety and depression were found to be the most commonly experienced psychiatric manifestations among psychiatric and emergency health-care workers.
Evidence showed the prevalence of psychosocial distress close to be $30 \%$ or higher among those who work in high demand area with low control like the emergency room (ER).[8]

\section{Subjects and Methods}

This is across sectional comparative study in $\mathrm{Al}$ Maamoura Mental Hospital and Al Maamoura Chest Hospital. The study was carried out from January 2018 till Decemeber 2018.

The sample was randomly selected from staff members and workers from both hospitals (60 subjects from Al Maamours Mental Hospital and 120 subjects from Al Maamoura Chest Hospital) fulfilling the inclusion criteria, both genders (males and females) of age group between 18 and 60 years, and all participants are regularly working not on vacations. And staff members with medical or neurological disorders were excluded.

The interview included demographic data as age, sex, education, occupation, residency, marital status, personal past and family history, type of job, sick leaves and years of experiences.

Neurological, physical and psychiatric examination was made to exclude disorders and comorbidity.

The Taylor anxiety scale was used: It consists of 50 true or false questions. The replies indicating anxiety are counted, giving a score from 0 to 50 with the higher score representing a higher level of anxiety [9]. 
3. Results

Table (1) Sociodemographic data of participant from Maamoura Mental and Chest Hospitals.

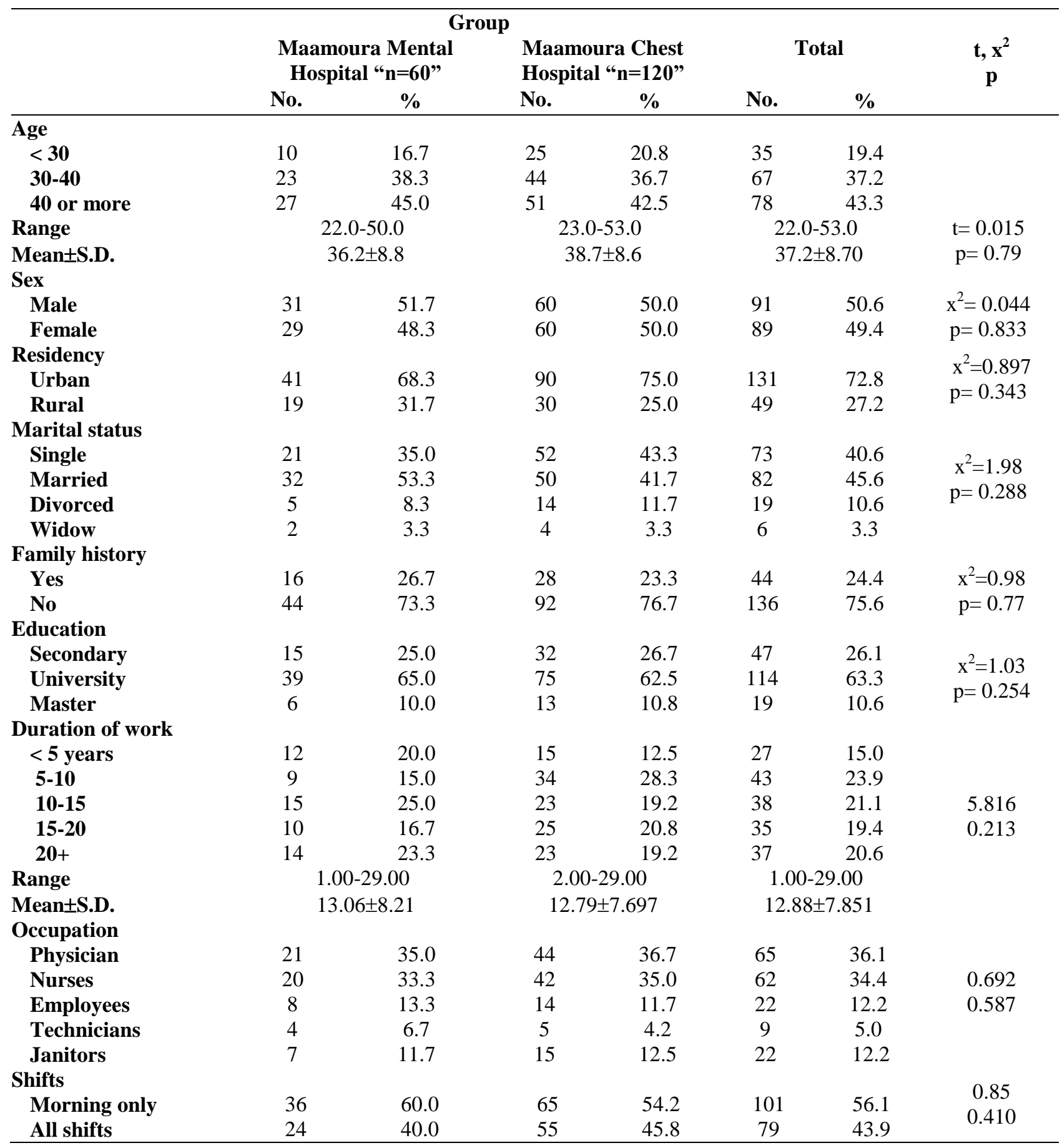

Table (2) Prevalence of anxiety in Maamoura mental hospital

\begin{tabular}{|c|c|c|}
\hline \multirow{2}{*}{ Taylor anxiety rating scale } & \multicolumn{2}{|c|}{ Maamoura Mental Hospital " $n=60$ " } \\
\hline & No. & $\%$ \\
\hline Free of anxiety & 14 & $23.3 \%$ \\
\hline Simple anxiety & 7 & $11.7 \%$ \\
\hline Somewhat anxiety & 19 & $31.7 \%$ \\
\hline Intense anxiety & 4 & $6.7 \%$ \\
\hline Very intense anxiety & 16 & $26.7 \%$ \\
\hline
\end{tabular}

On Taylor anxiety rating scale 14(23.3\%) participants were free from anxiety. 
Table (3) Comparison between Maamoura Mental Hospital and Maamoura Chest Hospital according to Taylor anxiety rating scale regarding demographic data.

\begin{tabular}{|c|c|c|c|c|c|c|c|c|c|c|c|c|c|}
\hline \multirow{3}{*}{$\begin{array}{l}\text { Taylor anxiety } \\
\text { rating scale }\end{array}$} & \multicolumn{13}{|c|}{ Maamoura Mental Hospital } \\
\hline & \multirow[t]{2}{*}{ Total } & \multicolumn{2}{|c|}{$\begin{array}{l}\text { Free of } \\
\text { anxiety }\end{array}$} & \multicolumn{2}{|c|}{$\begin{array}{c}\text { simple } \\
\text { anxiety }\end{array}$} & \multicolumn{2}{|c|}{$\begin{array}{l}\text { Somewhat } \\
\text { anxiety }\end{array}$} & \multicolumn{2}{|c|}{$\begin{array}{l}\text { Intense } \\
\text { anxiety }\end{array}$} & \multicolumn{2}{|c|}{$\begin{array}{c}\text { Very intense } \\
\text { anxiety }\end{array}$} & \multirow[t]{2}{*}{$\mathbf{X}^{2}$} & \multirow[t]{2}{*}{$\mathbf{P}$} \\
\hline & & No & $\%$ & No & $\%$ & No & $\%$ & No & $\%$ & No & $\%$ & & \\
\hline \multicolumn{14}{|l|}{ Age (years) } \\
\hline$<30$ & 10 & 9 & 90.0 & 0 & 0.0 & 1 & 10.0 & 0 & 0.0 & 0 & 0.0 & 51.40 & $0.001 *$ \\
\hline $30-40$ & 23 & 5 & 21.7 & 6 & 26.1 & 10 & 43.5 & 0 & 0.0 & 2 & 8.7 & & \\
\hline 40 or more & 27 & 0 & 0.0 & 1 & 3.7 & 8 & 29.6 & 4 & 14.8 & 14 & 51.9 & & \\
\hline Sex & & & & & & & & & & & & 6.36 & 0.17 \\
\hline Male & 31 & 6 & 19.4 & 1 & 3.2 & 12 & 38.7 & 3 & 9.7 & 9 & 29.0 & & \\
\hline Female & 29 & 8 & 27.6 & 6 & 20.7 & 7 & 24.1 & 1 & 3.4 & 7 & 24.1 & & \\
\hline \multicolumn{14}{|l|}{ Marital status } \\
\hline Single & 21 & 6 & 28.6 & 3 & 14.3 & 5 & 23.8 & 2 & 9.5 & 5 & 23.8 & 2.12 & 0.33 \\
\hline Married & 32 & 6 & 18.8 & 3 & 9.4 & 11 & 34.4 & 2 & 6.3 & 10 & 31.3 & & \\
\hline Divorced & 5 & 2 & 40.0 & 1 & 20.0 & 1 & 20.0 & 0 & 0.0 & 1 & 20.0 & & \\
\hline Widow & 2 & 0 & 0.0 & 0 & 0.0 & 2 & 100.0 & 0 & 0.0 & 0 & 0.0 & & \\
\hline \multicolumn{14}{|l|}{ Residence } \\
\hline Rural & 41 & 12 & 29.3 & 5 & 12.2 & 13 & 31.7 & 2 & 4.9 & 9 & 22.0 & 1.65 & 0.41 \\
\hline Urban & 19 & 2 & 10.5 & 2 & 10.5 & 6 & 31.6 & 2 & 10.5 & 7 & 36.8 & & \\
\hline \multicolumn{14}{|l|}{ Education } \\
\hline Secondary & 15 & 3 & 20.0 & 1 & 6.7 & 8 & 53.3 & 0 & 0.0 & 3 & 20.0 & 14.653 & 0.066 \\
\hline Faculty & 39 & 10 & 25.6 & 3 & 7.7 & 10 & 25.6 & 4 & 10.3 & 12 & 30.8 & & \\
\hline Master & 6 & 1 & 20.0 & 3 & 60.0 & 1 & 20.0 & 0 & 0.0 & 1 & 20.0 & & \\
\hline \multicolumn{14}{|l|}{ Family history } \\
\hline No & 44 & 12 & 27.3 & 5 & 11.4 & 12 & 27.3 & 3 & 6.8 & 12 & 27.3 & 2.145 & 0.709 \\
\hline Yes & 16 & 2 & 12.5 & 2 & 12.5 & 7 & 43.8 & 1 & 6.3 & 4 & 25.0 & & \\
\hline \multicolumn{14}{|c|}{ Maamoura Chest Hospital } \\
\hline \multicolumn{14}{|l|}{ Age (years) } \\
\hline$<30$ & 25 & 23 & 92.0 & 1 & 4.0 & 1 & 4.0 & 0 & 0.0 & 0 & 0.0 & 68.80 & 0.001 \\
\hline $30-40$ & 44 & 27 & 61.4 & 6 & 13.6 & 11 & 25.0 & 0 & 0.0 & 0 & 0.0 & & \\
\hline 40 or more & 51 & 2 & 3.9 & 15 & 29.4 & 20 & 39.2 & 4 & 7.8 & 10 & 19.6 & & \\
\hline Sex & & & & & & & & & & & & 3.775 & 0.437 \\
\hline Male & 60 & 31 & 51.7 & 9 & 15.0 & 13 & 21.7 & 2 & 3.3 & 5 & 8.3 & & \\
\hline Female & 60 & 21 & 35.0 & 13 & 21.7 & 19 & 31.7 & 2 & 3.3 & 5 & 8.3 & & \\
\hline \multicolumn{14}{|l|}{ Marital status } \\
\hline Single & 52 & 24 & 46.2 & 8 & 15.4 & 12 & 23.1 & 2 & 3.8 & 6 & 11.5 & 9.21 & $0.018 *$ \\
\hline Married & 50 & 16 & 32.0 & 12 & 24.0 & 16 & 32.0 & 2 & 4.0 & 4 & 8.0 & & \\
\hline Divorced & 14 & 10 & 71.4 & 2 & 14.3 & 2 & 14.3 & 0 & 0.0 & 0 & 0.0 & & \\
\hline Widow & 4 & 2 & 50.0 & 0 & 0.0 & 2 & 50.0 & 0 & 0.0 & 0 & 0.0 & & \\
\hline Residence & & & & & & & & & & & & & \\
\hline Rural & 90 & 42 & 46.7 & 18 & 20.0 & 19 & 21.1 & 3 & 3.3 & 8 & 8.9 & 2.01 & 0.31 \\
\hline Urban & 30 & 10 & 33.3 & 4 & 13.3 & 13 & 43.3 & 1 & 3.3 & 2 & 6.7 & & \\
\hline Education & & & & & & & & & & & & & \\
\hline Secondary & 32 & 13 & 40.6 & 5 & 15.6 & 8 & 25.0 & 0 & 0.0 & 6 & 18.8 & 10.468 & 0.234 \\
\hline Faculty & 75 & 33 & 44.0 & 13 & 17.3 & 22 & 29.3 & 4 & 5.3 & 3 & 4.0 & & \\
\hline Master & 13 & 6 & 46.2 & 4 & 30.8 & 2 & 15.4 & 0 & 0.0 & 1 & 7.7 & & \\
\hline Family history & & & & & & & & & & & & & \\
\hline No & 92 & 40 & 43.5 & 15 & 16.3 & 28 & 30.4 & 2 & 2.2 & 7 & 7.6 & 2.145 & 0.709 \\
\hline Yes & 28 & 12 & 42.9 & 7 & 25.0 & 4 & 14.3 & 2 & 7.1 & 3 & 10.7 & & \\
\hline
\end{tabular}


Table (4) Comparison between Maamoura Mental Hospital and Maamoura Chest Hospital according to Taylor anxiety rating scale regarding occupation data.

\begin{tabular}{|c|c|c|c|c|c|c|c|c|c|c|c|c|c|}
\hline \multicolumn{2}{|c|}{$\begin{array}{c}\text { Taylor anxiety rating } \\
\text { scale }\end{array}$} & \multicolumn{12}{|c|}{ Maamoura Mental Hospital } \\
\hline & \multirow[t]{2}{*}{ Total } & \multicolumn{2}{|c|}{$\begin{array}{l}\text { Free of } \\
\text { anxiety }\end{array}$} & \multicolumn{2}{|c|}{$\begin{array}{l}\text { simple } \\
\text { anxiety }\end{array}$} & \multicolumn{2}{|c|}{$\begin{array}{l}\text { Somewhat } \\
\text { anxiety }\end{array}$} & \multicolumn{2}{|c|}{$\begin{array}{l}\text { Intense } \\
\text { anxiety }\end{array}$} & \multicolumn{2}{|c|}{$\begin{array}{l}\text { Very } \\
\text { intense } \\
\text { anxiety }\end{array}$} & \multirow[t]{2}{*}{$\mathbf{X}^{2}$} & \multirow[t]{2}{*}{$\mathbf{P}$} \\
\hline & & No & $\%$ & No & $\%$ & No & $\%$ & No & $\%$ & No & $\%$ & & \\
\hline \multicolumn{14}{|l|}{ Shift } \\
\hline Morning only & 36 & 10 & 27.8 & 3 & 8.3 & 8 & 22.2 & 3 & 8.3 & 12 & 33.3 & \multirow[t]{2}{*}{4.65} & \multirow[t]{2}{*}{$0.03 *$} \\
\hline All shifts & 24 & 4 & 16.7 & 4 & 16.7 & 11 & 45.8 & 1 & 4.2 & 4 & 16.7 & & \\
\hline \multicolumn{14}{|l|}{ Duration of work } \\
\hline$<5$ years & 12 & 12 & 100.0 & 0 & 0.0 & 0 & 0.0 & 0 & 0.0 & 0 & 0.0 & \multirow{5}{*}{7.04} & \multirow{5}{*}{$0.034^{*}$} \\
\hline $5-10$ & 9 & 2 & 22.2 & 1 & 11.1 & 6 & 66.7 & 0 & 0.0 & 0 & 0.0 & & \\
\hline $10-15$ & 15 & 0 & 0.0 & 6 & 40.0 & 6 & 40.0 & 0 & 0.0 & 3 & 20.0 & & \\
\hline $15-20$ & 10 & 0 & 0.0 & 0 & 0.0 & 5 & 50.0 & 0 & 0.0 & 5 & 50.0 & & \\
\hline $20+$ & 14 & 0 & 0.0 & 0 & 0.0 & 2 & 14.3 & 4 & 28.6 & 8 & 57.1 & & \\
\hline \multicolumn{14}{|l|}{ Occupation } \\
\hline Physician & 21 & 4 & 19.0 & 4 & 19.0 & 6 & 28.6 & 2 & 9.5 & 5 & 23.8 & \multirow{5}{*}{13.44} & \multirow{5}{*}{0.640} \\
\hline Nurses & 20 & 4 & 20.0 & 2 & 10.0 & 4 & 20.0 & 2 & 10.0 & 8 & 40.0 & & \\
\hline Employees & 8 & 3 & 37.5 & 1 & 12.5 & 2 & 25.0 & 0 & 0.0 & 2 & 25.0 & & \\
\hline Technicians & 4 & 1 & 25.0 & 0 & 0.0 & 2 & 50.0 & 0 & 0.0 & 1 & 25.0 & & \\
\hline Janitors & 7 & 2 & 28.6 & 0 & 0.0 & 5 & 71.4 & 0 & 0.0 & 0 & 0.0 & & \\
\hline \multicolumn{14}{|c|}{ Maamoura Chest Hospital } \\
\hline \multicolumn{14}{|l|}{ Shift } \\
\hline Morning only & 65 & 29 & 44.6 & 10 & 15.4 & 18 & 27.7 & 3 & 4.6 & 5 & 7.7 & \multirow[t]{2}{*}{2.15} & \multirow[t]{2}{*}{0.211} \\
\hline All shifts & 55 & 23 & 41.8 & 12 & 21.8 & 14 & 25.5 & 1 & 1.8 & 5 & 9.1 & & \\
\hline \multicolumn{14}{|l|}{ Duration of work } \\
\hline$<5$ years & 15 & 15 & 100.0 & 0 & 0.0 & 0 & 0.0 & 0 & 0.0 & 0 & 0.0 & \multirow{5}{*}{15.121} & \\
\hline $5-10$ & 34 & 32 & 94.1 & 0 & 0.0 & 2 & 5.9 & 0 & 0.0 & 0 & 0.0 & & \\
\hline $10-15$ & 23 & 2 & 8.7 & 8 & 34.8 & 13 & 56.5 & 0 & 0.0 & 0 & 0.0 & & $0.01 *$ \\
\hline $15-20$ & 25 & 3 & 12.0 & 11 & 44.0 & 11 & 44.0 & 0 & 0.0 & 0 & 0.0 & & \\
\hline $20+$ & 23 & 0 & 0.0 & 3 & 13.0 & 6 & 26.1 & 4 & 17.4 & 10 & 43.5 & & \\
\hline Occupation & & & & & & & & & & & & & \\
\hline Physician & 44 & 22 & 50.0 & 8 & 18.2 & 8 & 18.2 & 2 & 4.5 & 4 & 9.1 & & \\
\hline Nurses & 42 & 16 & 38.1 & 9 & 21.4 & 15 & 35.7 & 2 & 4.8 & 0 & 0.0 & & \\
\hline Employees & 14 & 5 & 35.7 & 3 & 21.4 & 5 & 35.7 & 0 & 0.0 & 1 & 7.1 & 17.92 & 0.328 \\
\hline Technicians & 5 & 3 & 60.0 & 0 & 0.0 & 1 & 20.0 & 0 & 0.0 & 1 & 20.0 & & \\
\hline Janitors & 15 & 6 & 40.0 & 2 & 13.3 & 3 & 20.0 & 0 & 0.0 & 4 & 26.7 & & \\
\hline
\end{tabular}

\section{Discussion}

Anxiety disorders are a type of mental health condition. Anxiety makes it difficult to get through your day, symptoms include feeling of nervousness, panic and fear as well as sweating and rapid heartbeats. Treatments include medications and cognitive behavioural therapy [10]

Anxiety disorders include disorders that share features of excessive fear and anxiety and related behavioural disturbances. Fear is the emotional response to real or perceived imminent threat, while anxiety is anticipation of future threat, these two states overlap but also differ. The anxiety disorders differ from one another in the types of objectives or situations that induce fear, anxiety or avoidance behaviour and the associated cognitive ideation [11]

Factors causing anxiety among workers are increasing and psychosocial causes are the most common.
Psychosocial factors refer to the interactions within the work environment, job content, organizational conditions and workers capacities, needs, culture, personal extra job considerations, that may through perceptions and experience influence health, work performance and job satisfaction [12]

Psychosocial factors are presents in all types of organizations and depending on the empolyees individual differences, they can be perceived as threatening for their health, or by contrast, if there is an optimal balance between working conditions and individual characteristics, work can become a source of health wellbeing, satisfaction and motivation [13]

Thus, the need for a study about the anxiety and stress related factors of the governmental hospitals and the Egyptian culture was the reason behind the current research. This is a cross sectional comparative study not only between mental and chest 
hospital staff but also between the different type of work among them, moreover it was aimed at:

1) Assessing the anxiety levels among those who work in mental hospitals.

2) Different factors that might be the cause of anxiety were assessed as age, sex, residency, marital status, family history, education, occupation, duration and shifts of work.

The strength of this study is using a valid reliable and brief structured psychiatry interview questionnaire, Taylor anxiety rating scale covering the sample from both hospitals, Maamoura Mental Hospital and Maamoura Chest Hospital.

Regarding socio-demographic and occupational data of the studied participants from Al Maamoura Mental Hospital and Al Mamoura Chest Hospital.

Table (1) shows that there was no statistically significant difference between the two hospitals regarding age, sex, residency, family history, education, occupation, shifts and duration of work.

Age in Maamoura Mental Hospital ranged from 22-50 and in Maamoura Chest Hospital ranged from 23-53. Males in Maamoura Mental Hospital were 31 and females were 29 while in Maamoura Chest Hospital were the same for each 60. Regarding to residency, urban residents in Maamoura Mental Hospital were41 and rural were 19, while in Maamoura Chest Hospital were 90 and 30 respectively. In Mental Hospital single participants were 21 , married 32 , divorced 5 , widow 2 , while in Chest Hospital were 52, 50, 14, 4 respectively. +ve mental family history in Mental Hospital was 16, -ve was 44, while in Maamoura Chest Hospital were 28 and 92 respectively. Education in Mental Hospital were 15 secondary, university 39 and high 6 .

While in Chest Hospital were 32, 75, 13 respectively. Duration of work in Mental Hospital < $5 y$ is $12,5-10 \mathrm{y}$ is $9,10-15 \mathrm{y}$ is $15,15-20 \mathrm{y}$ is 10 and $>20 \mathrm{y}$ is 14 , while in Chest Hospital were 15, 34, 23, 25,23 respectively. Occupation in Mental Hospital were physician 21, nurses 20, employees 8, technicians 4 and janitors 7 , while in Chest Hospital were 44, 42, 14, 5, 15 respectively. Shifts of work in Mental Hospital were morning only 36 and all shifts 24, while in Chest Hospital were 65 and 55 respectively.

The urban residents were more than rural because Maamoura is part of the city in Alexandria. Increasing the number of married subjects is common as the chosen age group is from the middle age. Increasing the number of university degrees may be due to the type of work in the sample which requires a degree.

The number of morning shifts increase because many subjects prefer to work during morning more than all shifts and as many were clerks.

Regarding prevalence of anxiety in Al Maamoura Mental Hospital. Table (2) shows on Taylor anxiety rating scale $14(23.3 \%)$ participants were free from anxiety and $46(76.7 \%)$ participants were suffering from anxiety with different degrees, 16 participants of these 46 were having severe anxiety.

National survey of prevalence of mental disorders in Egypt conducted a door to door house hold survey of 14640 adults aged from 18 to 64 years in 6 regions in Egypt. Mental disorders were diagnosed using MINI plus diagnostic interview, overall prevalence was estimated at $16.93 \%$ of the studied adult population. The main problems were mood disorders $6.73 \%$, anxiety disorders $7.75 \%$ and multiple disorders $7.72 \%$. Thus, these results are much less than the current data.

Mental disorders were associated with sociodemographic factors (e.g being female, being unemployed, being divorced) and physical illness (e.g heart disease, kidney disease, hypertension) [14].

Table (3) clarifies that anxiety increases with age in both Chest and Mental Hospitals but increases in Chest Hospital more than Mental Hospital. 27subjects (45\%) in mental hospital and 49(40.83\%) in chest hospital.

Compared with younger workers, older workers reported higher levels of anxiety. Health workers, 31 years and older were found to have statistically higher state anxiety [15]

Regarding sex anxiety increase in males in the Mental Hospital but decrease in the Chest Hospital in males and increase in females, 25 males in the Mental Hospital and 39 females in the Chest Hospital.

Anxiety in general has been more observed in females than males [16].

Women have reported higher levels of anxiety than men studied of physicians in China. [17]

Regarding marital status anxiety increase in married subjects in both hospitals 26(43.33\%) in Mental Hospital and 34(28.33\%) in Chest Hospital. Probably the increased burdens and financial demands increase in marriage and that increases the anxiety.

Regarding residence anxiety increase in rural than urban in Maamoura Mental hospital 29(48.33\%) versus $48(28 \%)$ in Chest Hospital. May be the ones working in mental hospital becomes more aware of mental disorders even when they are coming from rural areas.

Regarding education anxiety increase in subjects with a master degree in Mental hospital $(83.33 \%)$ than those of secondary or high degrees. While the highest degree of anxiety was among those with secondary degree, then faculty then Masters (59.375) (56\%) and (53.84\%) respectively in chest hospital. Probably in the Mental hospital those with the masters degree are the physicians and they are stressed and overloaded and more aware about anxiety.

Regarding family history, anxiety was not significantly related to those who have +ve family history of mental disorders in both hospitals, 
$14(87.5 \%)$ in Mental Hospital and 16(57.14\%) in Chest Hospital.

Regarding shifts of work, anxiety increase in those having different shifts in the Mental Hospital $(83.33 \%)$, while results were almost the same in the Chest Hospital. It would have been assumed that having different working hours would lead to more anxiety.

Regarding duration of work in Mental Hospital the anxiety statistically significantly increases in those who worked 10-15 and above 15 years but in Chest Hospital it is highly statistically significantly increased with increase the duration of work $>15$ years.

Regarding the occupation in Mental Hospital anxiety increase in physicians but in Chest Hospitals increase in nurses, 17 in Mental Hospital and 26 in Chest Hospital.

Finally it was noticed that anxiety increase in Chest Hospital than in Mental Hospital.

The nursing staff had more anxiety than physicians and other non medical staff. [18]

Anxiety was significantly associated with work related events such as changes in working hours and conditions. [19]

Regarding to anxiety scores, no significant differences were found by gender, age, education, marital status, prescience of children, source of income, profession and daily work hours, that anxiety scores for health care workers who worked overtime and were assigned shift work were significantly higher than other groups[15]

Another study of 717 participants of the role of socio-demographic factors in depression and anxiety resulted122(29.7\%)had depression and179(35.9\%)had anxiety. Depression and anxiety were significantly associated with females, low level of education, increased age, poor financial situation and marital status [20]

\section{Conclusion}

- On Taylor anxiety rating scale the prevalence of anxiety in Maamoura Mental Hospital was $46(76.7 \%)$ were suffering from anxiety with different degrees,and $16(26.7 \%)$ of this 46 were very intense anxiety.

- On Taylor anxiety rating scale anxiety increase with age, males, married, rural residence, faculty degree, morning shifts increase the duration of work, in nurses and not related to +ve mental family history.

- The study concluded increase anxiety in the chest hospital than in Mental Hospital.

\section{References}

[1] S.Niknamian The Impact of Stress, Anxiety, Fear and Depression in the Cause of Cancer In Humans. PsyArXiv, 2019.

[2] IG.Franzoi, MD.Sauta, A. Granieri, State and Trait Anxiety Among University Students: A Moderated Mediation Model of
Negative Affectivity, Alexithymia, and Housing Conditions. Front Psychol.vol.11,pp.1255,2020.

[3] World Health Organization and Calouste Gulbenkian Foundation. Social determinants of mental health. Geneva, World Health Organization,2014.

[4] P.Sarafis, E.Rousaki, A.Tsounis, et al. The impact of occupational stress on nurses' caring behaviors and their health related quality of life. BMC Nurs.vol.15,pp.56,2016.

[5] K.Atif, HU.Khan, MZ.Ullah, FS.Shah, A.Latif, Prevalence of anxiety and depression among doctors; the unscreened and undiagnosed clientele in Lahore, Pakistan. Pak J Med Sci.vol.32(2),pp.294298,2016.

[6] Y.Gong, T.Han, W.Chen, et al. Prevalence of anxiety and depressive symptoms and related risk factors among physicians in China: a cross-sectional study. PLoS One.vol.9(7),pp.e103242,2014.

[7] A.Shajan, C.Nisha, Anxiety and Depression among nurses working in a tertiary care hospital in South India. Int $\mathbf{J} \mathrm{Adv}$ Med.vol.6,pp.1611- 5,2019.

[8] N.Burton Psychiatry. 2nd edition. Oxford: Wiley-Blackwell; 2011.

[9] Taylor, Janet "A personality scale of manifest anxiety". The Journal of Abnormal and Social Psychology.vol.48 (2),pp.285290,1953.

[10] American Psychiatric Association,2020.

[11] S.DSH, Anxiety chapter ,pp.189.

[12] Williams, Buxton, Hinde, Bray and Berkman. Psychosocial work place factors and health care utilization: A study of two employers. International Journal of Health Policy and Management,2017.

[13] Lorente, Salanova, Martinez, Vera. How personal resources predict work engagement and self-related performance among construction workers: A social cognitive perspective International Journal of Psychiatry ,2017.

[14] Eastern Mediterranean Health Journal .vol.15,2009.

[15] MD.Metin Picakciefe, PhD1.Aynur Turgut, RN1.Emel Igneci, RN1.Fatih Cayli, RN1.Artuner Deveci, Relationship Between Socio-Demographic Features, Work-Related Conditions, and Level of Anxiety Among Turkish Primary Health Care Workers.vol.63,pp.501-511,2015.

[16] S.Canabaz, C.Dundar, F.Canbak, AF.Sunter, Y.Pekseken, EC.Cetinoglu , Violence towards workers in hospital emergency services and in emergency medical care units in Samsun. An epidemiological study. 
Ulus trauma Acil cerrabi Derg.vol.17,pp.239-244,2008.

[17] Y.Gong, T.Han, W.Chen, et al. Prevalence of anxiety and depressive symptoms and related risk factors among physicians in China: a cross-sectional study. PLoS One.vol.9(7),pp.e103242,2014.
[18] G.Preti, V.Matti, G.Perego et al. The psychological impact of epidemic and pandemic out breaks on health care workers, 2020.

[19] Rose et al,2006.

[20] G.Gerogianni. Int Urol Nephrol ,2018. 